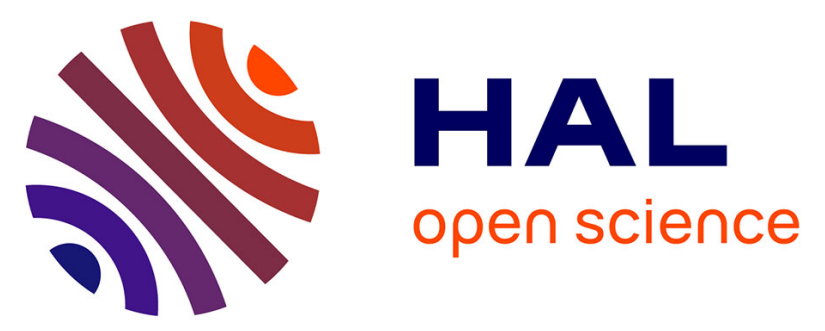

\title{
Sn-Li Transmetalation of $\alpha$-Aminoorganostannanes for the Stereoselective Synthesis of Substituted Dehydropiperidines and Dehydroazepanes
}

\author{
Alexandre Lumbroso, Isabelle Beaudet, Jean-Paul Quintard, Cécile Fraisse, \\ Nicolas Galland, Loic Toupet, Erwan Le Grognec
}

\section{To cite this version:}

Alexandre Lumbroso, Isabelle Beaudet, Jean-Paul Quintard, Cécile Fraisse, Nicolas Galland, et al.. Sn-Li Transmetalation of $\alpha$-Aminoorganostannanes for the Stereoselective Synthesis of Substituted Dehydropiperidines and Dehydroazepanes. Advanced Synthesis and Catalysis, 2019, 361 (16), pp.37773786. 10.1002/adsc.201900349 . hal-03017578

\section{HAL Id: hal-03017578 https://hal.science/hal-03017578}

Submitted on 21 Nov 2020

HAL is a multi-disciplinary open access archive for the deposit and dissemination of scientific research documents, whether they are published or not. The documents may come from teaching and research institutions in France or abroad, or from public or private research centers.
L'archive ouverte pluridisciplinaire HAL, est destinée au dépôt et à la diffusion de documents scientifiques de niveau recherche, publiés ou non, émanant des établissements d'enseignement et de recherche français ou étrangers, des laboratoires publics ou privés. 


\title{
Sn-Li Transmetalation of $\alpha$-Aminoorganostannanes for the Stereoselective Synthesis of Substituted Dehydropiperidines and Dehydroazepanes
}

\author{
Alexandre Lumbroso, ${ }^{\mathrm{a}}$ Isabelle Beaudet, ${ }^{\mathrm{a}}$ Jean-Paul Quintard, ${ }^{\mathrm{a}}$ Cécile Fraisse, ${ }^{\mathrm{a}}$ Nicolas Galland, \\ Loïc Toupet, ${ }^{\mathrm{b}}$ Erwan Le Grognec ${ }^{\text {a* }}$ \\ a Université de Nantes, CNRS, CEISAM, UMR 6230, F-44000 Nantes, France. \\ e-mail: erwan.legrognec@univ-nantes.fr \\ b Université de Rennes 1, CNRS UMR 6251, Institut de Physique de Rennes, Campus de Beaulieu, 35042 Rennes, \\ France.
}

\begin{abstract}
A highly diastereoselective synthesis of $(R, S)$ or $(S, S)$ 2,6-disubstituted dehydropiperidines and 2,7-disubstituted dehydroazepanes has been developed. The stereochemical preference for the $(R, S)$ or the $(S, S)$ isomer is governed by a tin-lithium exchange/electrophilic trapping sequence combined with a ring-closing metathesis. Their relative order was found to have a dramatic influence on the interaction controlling the epimerization at the anionic center. In each case, the complete stereodivergence of the reactions sequence is explained by considering the stabilization brought by the lithium-carbonyl coordination and rationalized by DFT calculations. Keywords: Tin, Lithium, Sn-Li exchange, Chiral carbanion, DFT calculations, Ring-closing metathesis, Dehydropiperidines
\end{abstract}




\section{Introduction}

Functionalized piperidines are widely present in alkaloids and bioactive compounds, therefore many methodologies have been developed to prepare these six-membered ring heterocycles. ${ }^{[1]}$ Moreover, polyhydroxylated piperidines (named iminosugars or iminocyclitols) constitute the most attractive carbohydrate mimetics reported to date and can act as glycosidase or glycosyltransferase inhibitors. ${ }^{[2]}$ For these applications, it is essential to control the stereocenter configuration of the piperidines and especially at the 2 and 6 positions since they define the series of sugars they mimic. ${ }^{[3]}$ In this context, the stereocontrolled synthesis of 2,6-disubstituted dehydropiperidines, which can be used as precursors of 2,6-disubstituted piperidines, presents a strong interest. Having in hand a series of 2-stannylated dehydropiperidines precursors, ${ }^{[4]}$ we have evaluated their interest for the stereoselective synthesis of 2,6-disubstituted-3,4-dehydropiperidines through a sequence involving a Sn-Li transmetalation and an electrophilic trapping. We also considered this strategy for the synthesis of dehydroazepanes, since polyhydroxylated azepanes are also present in biological active products and have received some attention. ${ }^{[5]}$

The Sn-Li transmetalation of organostannanes by organolithium reagents is an efficient reaction which has been applied to aryltins, heteroaryltins, vinyltins, allyltins or $\alpha$-heterosubstituted organotins. ${ }^{[6]}$ When applied to $\alpha$-oxygenated organostannanes to prepare $\alpha$-oxygenated organolithium reagents, this reaction can be highly stereoselective when achieved at low temperature, although sensitive to steric hindrance. ${ }^{[7]}$ Similarly, $\alpha$ nitrogenated organolithium reagents can be obtained by Sn-Li transmetalation from the corresponding organostannyl precursors. However, in this case the stereoselectivity is highly dependent on the temperature, the solvent and the nitrogen protecting group. ${ }^{[8]}$ Previous studies have shown that a $N$-carbamoyl protection allows a stabilization of the desired lithiated species. ${ }^{[9]}$ Moreover, the Sn-Li transmetalation of 2-organostannyl1,3-oxazolidinones affords organolithium derivatives having a higher trend to epimerize into the isomer allowing the most stabilizing coordination. ${ }^{[10]}$ Based on these contributions, we assumed that the Sn-Li transmetalation of 2-stannylated dehydropiperidines protected as oxazolidinones could afford the corresponding anionic species with a control of the stereoselectivity.

We have previously examined the ring opening of 2-tributylstannyl-1,3-oxazolidines derived from (S)vinylglycinol by soft nucleophiles. This procedure allows an efficient access to 4-tributylstannyl-3-azadienyl alcohols 2 when alkenylmetals are used in the presence of a Lewis acid. ${ }^{[11]}$ These latter can be subsequently converted into the corresponding oxazolidinones $\mathbf{3}$ leading to the stannylated dehydropiperidines (or dehydroazepanes) 4 by ring closing metathesis. ${ }^{[4]}$ Following a preliminary communication, the aim of the present work is to study the $\mathrm{Sn}-\mathrm{Li}$ transmetalation reaction carried out on the stannylated oxazolidinones 3 and 4 by $n$-butyllithium in order to evaluate its diastereoselectivity and to rationalize the obtained results (Scheme 1). ${ }^{[12]}$

We first examined the transmetalation reaction of stannylated oxazolidinones $\mathbf{4}$ before considering those of 3. 

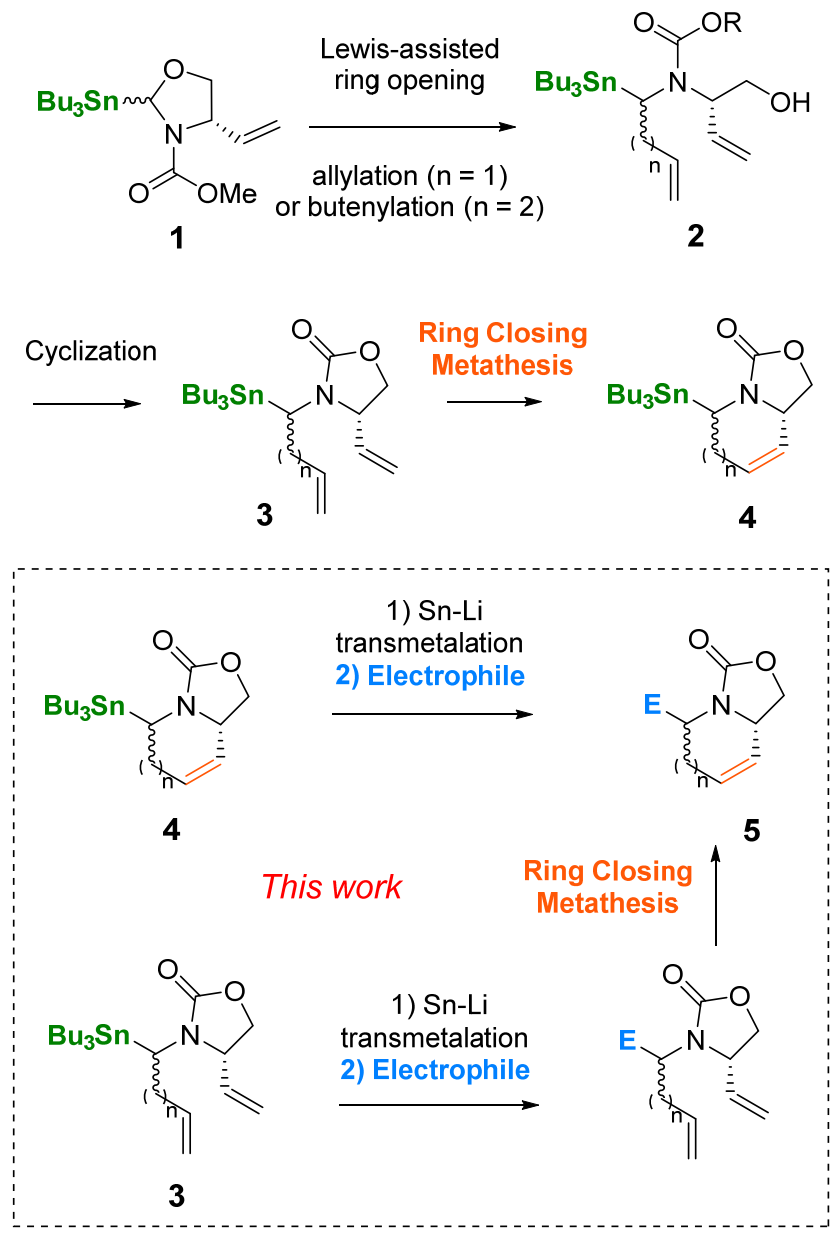

Scheme 1. Preparation and transmetalation of stannylated oxazolidinones 3 and $\mathbf{4}$.

\section{Results}

Transmetalation of stannylated oxazolidinones 4. Our investigations first focused on the $\mathrm{Sn}-\mathrm{Li}$ transmetalation reaction of enantiopure $N$-( $\alpha$-tributylstannylorgano)oxazolidin-2-ones $(R, S)$-4a and $(S, S)-\mathbf{4 a}$. The reaction was conducted at $-78^{\circ} \mathrm{C}$ in THF in the presence of $n$-BuLi (1.6 equiv.) and cyclohexanone was added after $20 \mathrm{~min}$. Under these standard experimental conditions, the $(S, S)-\mathbf{4 a}$ diastereomer afforded the 5a product as a single diastereomer in $72 \%$ yield (Table 1, entry 1 ). Suitable monocrystals for X-ray diffraction analysis were obtained and the absolute configuration was found to be $(R, S)$, indicating that the configuration of the stereocenter was preserved through the reactions.

Compound $(R, S)-\mathbf{5 a}$ was also obtained when the reaction sequence was carried out with $(R, S)-\mathbf{4 a}$, corresponding in this case to an inversion of configuration (entry 2), while the yield was found to be much lower (30\%). Starting from the $(S, S)-\mathbf{4 b}$ diastereomer, the 7-membered ring analogue, product $\mathbf{5 b}$ was selectively obtained as a single isomer in $79 \%$ yield (entry 3 ), and assigned to be $(R, S)-5 \mathbf{b}$ by analogy to $(R, S)$ 5a. This $(R, S)$-5b diastereomer was also selectively obtained in $58 \%$ yield when the reaction sequence was carried out starting from $(R, S)-\mathbf{4 b}$ (entry 4$)$. It indicates a high diastereoselectivity regardless of the configuration of the carbon bearing the tin moiety on the stannylated precursor and of the size of the bicyclic 
heterocycle. However, since higher yields were obtained after the transmetalation/trapping sequence when starting from $(S, S)$-4 instead of $(R, S)-\mathbf{4}$, the $(S, S)-\mathbf{4}$ isomer was systematically used in subsequent studies.

Under the same experimental conditions $\left(-78^{\circ} \mathrm{C}\right.$, THF), the transmetalation/trapping sequence carried out on $(S, S)-4 a$ proceeded with a good yield and a very high diastereoselectivity when $\mathrm{CO}_{2}(\mathrm{~g})$ was the electrophile. ${ }^{[12]}$ The Sn-Li exchange on $(S, S)-4$ a followed by electrophilic trapping was also proved to be efficient with benzaldehyde, isovaleraldehyde and hexanal as electrophiles, leading selectively to $(R, S)$ products, but as a couple of diastereomers due to the lack of diastereoselectivity on the aldehyde enantiotopic faces. The configuration of the major diastereomer of $7 \mathbf{a}$ was determined by X-ray diffraction analysis of suitable monocrystals and was found to be $(S, R, S)$. When the electrophile was benzaldehyde or isovaleraldehyde, the reaction temperature was lowered to $-90^{\circ} \mathrm{C}$ to avoid an intramolecular acyl transfer reaction occurring on one of the two diastereomers. ${ }^{[13]}$ This transfer results from an intramolecular attack of the alcoholate on the oxazolidinone, as it was previously reported for similar compounds. ${ }^{[14]}$ When hexanal was the electrophile, a temperature of $-100^{\circ} \mathrm{C}$ was required to prevent this side reaction. However, these experimental conditions dramatically impacted the yield (33\%) due to the concomitant formation of the hydrolysis product $\mathbf{1 0}$ resulting of a "frozen" reactivity of the lithiated intermediate. ${ }^{[13]}$ The absolute configuration of the 8a and 9a diastereomers were deduced from the comparison of their NMR spectra and $R_{F}$ values to those of $7 \mathbf{a}$ (see supporting information). 
Table 1. Sn-Li transmetalation followed by an electrophilic trapping of $\mathbf{4 a}$ and $\mathbf{4 b}$.

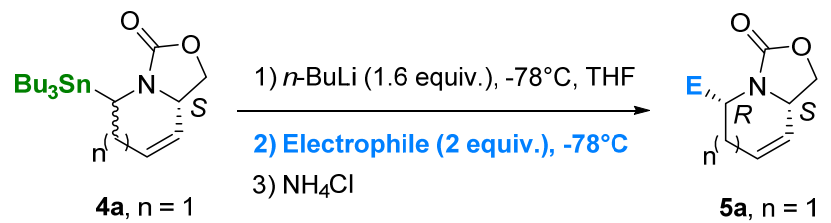

$\begin{array}{ll}\mathbf{4 a}, \mathrm{n}=1 & \mathbf{5 a}, \mathrm{n}=1 \\ \mathbf{4 b}, \mathrm{n}=2 & \mathbf{5 b}, \mathrm{n}=2\end{array}$

A. With cyclohexanone as electrophile

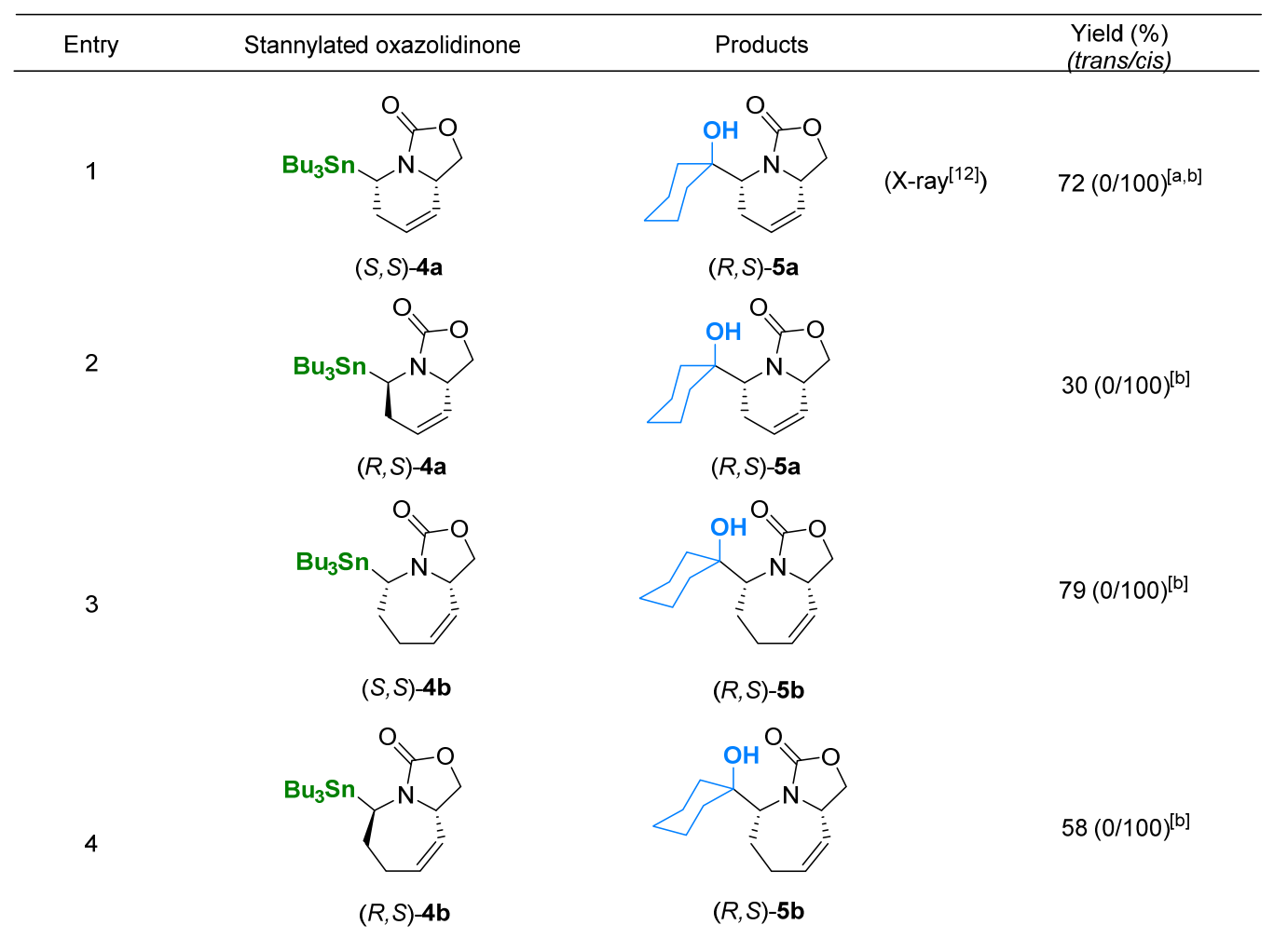

B. With other electrophiles starting from $(S, S)-4 a$

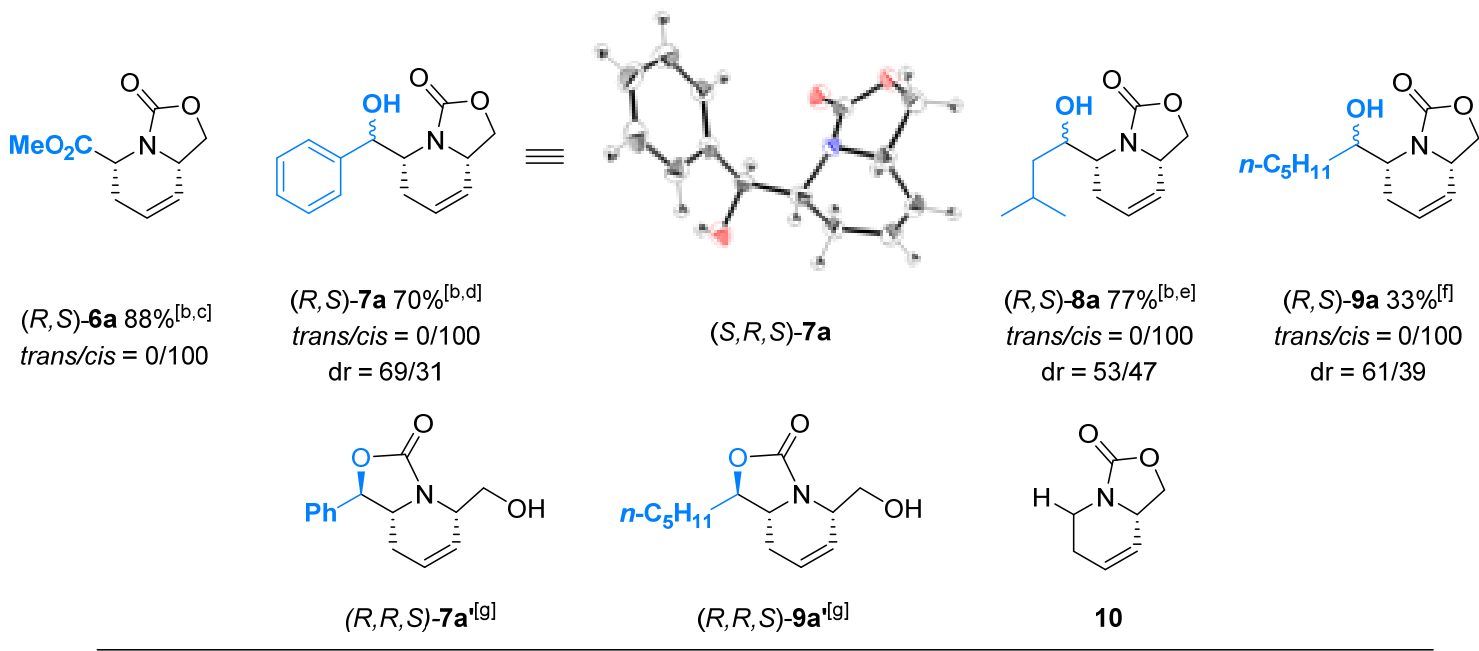

${ }^{[a]}$ The $(R, S)$ absolute configuration was confirmed by X-ray analysis.

${ }^{[b]} \mathrm{dr}$ was determined by GC on the crude products.

${ }^{[c]} \mathrm{CO}_{2}(\mathrm{~g})$ was used as electrophile followed by an esterification $\left(\mathrm{TMSCHN}_{2}\right.$ (1.3 equiv.), $\left.\mathrm{C}_{6} \mathrm{H}_{6}: \mathrm{MeOH}=4: 1\right)$.

[d] Benzaldehyde was used as electrophile and the temperature was lowered to $-90^{\circ} \mathrm{C}$; the configuration of the major compound $7 \mathbf{a}$ was determined to be $(S, R, S)$ by X-ray diffraction analysis.

[e] Isovaleraldehyde was used as electrophile and the temperature was lowered to $-90^{\circ} \mathrm{C}$.

[f] Hexanal was used as electrophile and the temperature was lowered to $-100^{\circ} \mathrm{C}$; $\mathrm{dr}$ was determined by ${ }^{1} \mathrm{H}$ NMR analysis.

${ }^{[\mathrm{g}]}$ Products resulting of an intramolecular acyl transfer reaction obtained when the reaction conditions were not optimized ${ }^{[13]}$ 
Transmetalation of stannylated oxazolidinones 3. We then turned our attention to $N-(\alpha-$ tributylstannylorgano) oxazolidin-2-ones 3a. A similar Sn-Li transmetalation/electrophilic trapping procedure was applied to these derivatives and the obtained results are presented in Table 2. With cyclohexanone as electrophile, diastereomer $(R, S)$-3a afforded product 11a in $71 \%$ yield as a single diastereomer (entry 1). Suitable monocrystals from 11a were obtained for X-ray diffraction analysis, allowing the determination of its $(S, S)$ absolute configuration, meaning that the configuration was preserved under these experimental conditions. Starting from the $(S, S)-\mathbf{3 a}$ diastereomer, the yield was found to be strongly lowered (entry 2, 47\%), but $(S, S)$-11a was obtained once more as a unique isomer when the reaction temperature was maintained at $-78^{\circ} \mathrm{C}$ (corresponding to a complete inversion of the configuration). The achievement of this reaction at $-100^{\circ} \mathrm{C}$ afforded 11a in good yield $(77 \%)$, but as a mixture of diastereomers (entry $3,(S, S) /(R, S)=26 / 74$ ) due to a partial epimerization of the chiral anionic center. Since higher yields were obtained after the transmetalation/trapping sequence when starting from $(R, S)$-3a instead of $(S, S)$-3a, the $(R, S)$-3 isomers were used in subsequent studies.

Starting from the $(R, S)$-3b diastereomer, bearing a butenyl group instead of an allyl group, product $\mathbf{1 1} \mathbf{b}$ was also selectively obtained as a single isomer in good yield (entry $4,82 \%)$. It was identified to be the $(S, S)$ diastereomer by analogy to $(S, S)-11 \mathbf{a}$. When the transmetalation was performed on $(R, S)-\mathbf{3 a}$ and the nonanone was used as the electrophilic trapping reagent, the $(S, S)$-12a product was isolated as a unique product but in $30 \%$ yield only, presumably because of the enolization reaction induced by the higher steric hindrance. The electrophilic trapping was also achieved with $\mathrm{CO}_{2}(\mathrm{~g})$ and, after esterification under neutral conditions with $\mathrm{TMSCHN}_{2}$, 13a was obtained in $76 \%$ yield with a strong $(S, S)$ preference $[(S, S)-\mathbf{1 3 a} /(R, S)-\mathbf{1 3 a}=97 / 3] .{ }^{[12]}$

We then looked at the use of aldehydes as electrophiles and, taking into account the possible occurrence of an intramolecular acyl transfer, the reaction temperature was fixed to $-90^{\circ} \mathrm{C}$. Starting from $(R, S)-\mathbf{3 a}$, the reaction products were obtained with an exclusive $(S)$-configuration at the previous anionic center whatever the nature of the aldehyde (benzaldehyde, isovaleraldehyde or hexanal). In every cases, the $(S, S)$-products were obtained selectively in good yields (74-81\%). Unfortunately, no diastereoselectivity was observed for the addition on the enantiotopic faces of these aromatic or aliphatic aldehydes $(\mathrm{dr}=58 / 42,50 / 50$ and 50/50, respectively). All these diastereomers were separated by column chromatography on silica gel. The absolute configuration of $(S, S, S)$-14a was based on that of $(S, S, S)-7 \mathbf{a}$ (vide infra), and those of 15a and 16a were deduced from the comparison of their NMR spectra and their $R_{F}$ with those of $\mathbf{1 4 a}$.

Finally, we have considered the introduction of an $n$-alkyl chain. While no reaction occurred when 1-iodohexane was used to trap the organolithium species, the desired coupling product 17a was obtained with a moderate $R, S$ selectivity if the organolithium intermediate was in situ converted into the corresponding organocopper reagent. The use of $\mathrm{CuCN} .2 \mathrm{LiCl}$ afforded 17a in $71 \%$ yield with a $(R, S) /(S, S)$ selectivity of $65 / 35$, while $\mathrm{CuCN}$ or pentynyl copper furnished low yields and minor stereoselectivity improvement (70/30 and 87/13 ratios, respectively, see supporting information).

Then, we focused on the ring-closing metathesis reaction of dienyl oxazolidinones 11-17 to prepare the dehydropiperidines (or dehydroazepanes) similar to those obtained previously from $\mathbf{4 a}$ (or $\mathbf{4 b}$ ) but with a 
different stereochemistry. Both Grubbs 1 and Grubbs 2 catalysts were considered for this reaction and the results are presented in Table 3.

The absolute configuration of all products listed in Table 3 were determined thanks to X-ray diffraction of suitable monocrystals of $(S, S)-\mathbf{5 a},(S, S)-\mathbf{5 b}$ and $(S, S, S)-\mathbf{7} \mathbf{a}$. These reactions were monitored by TLC and conversion rates over $90 \%$ were observed for the formation of the six membered rings with isolated yields in the range of $80-95 \%$ using Grubbs 1 catalyst at $25^{\circ} \mathrm{C}$ for 1 to $3 \mathrm{~h}$ or Grubbs 2 catalyst at $40^{\circ} \mathrm{C}$ for 1 to $6 \mathrm{~h}$. For the ring-closing metathesis of $(S, S)-\mathbf{1 1} \mathbf{b}$ with Grubbs 2 catalyst at $40^{\circ} \mathrm{C}$, the formation of a minor side product (identified as a regioisomer resulting from the migration of the double bond in the ring) was observed along with the formation of the expected one (Scheme 2). The $(S, S)-\mathbf{5 b} /(S, S)-\mathbf{5 b}$ ' ratio was found to be $89 / 11$ by ${ }^{1} \mathrm{H}$ NMR. The attempts to separate $(S, S)-\mathbf{5 b}$ ' from $(S, S)-\mathbf{5 b}$ were unsuccessful. However, by using Grubbs $1(10$ mol \%) at room temperature for $12 \mathrm{~h}$, the $(S, S)$-5b product was obtained exclusively in $51 \%$ isolated yield (Scheme 2). Such an isomerization has been previously observed and explained by a reversible addition of a ruthenium hydride complex on the double bond..$^{[4,15]}$

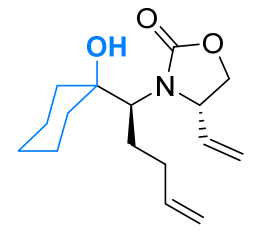

(S, S)-11b

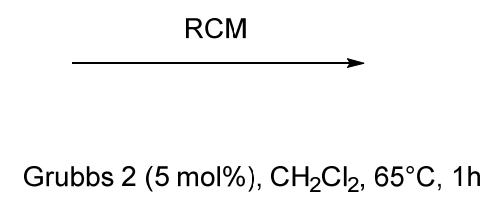

Grubbs 1 (10 mol\%), $\mathrm{CH}_{2} \mathrm{Cl}_{2}, 25^{\circ} \mathrm{C}, 12 \mathrm{~h}$

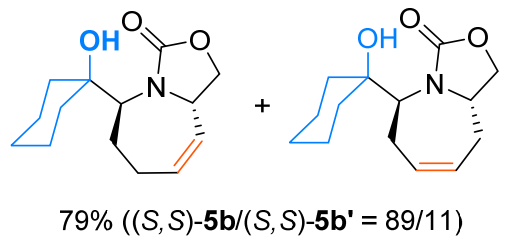

$51 \%\left((S, S)-5 \mathbf{b} /(S, S)-5 b^{\prime}=100 / 0\right)$

Scheme 2. Ring-closing metathesis of (S,S)-11b using Grubbs 1 or Grubbs 2 catalysts. 
Table 2. Sn-Li transmetalation followed by an electrophilic trapping of $\mathbf{3 a}$ and $\mathbf{3 b}$.

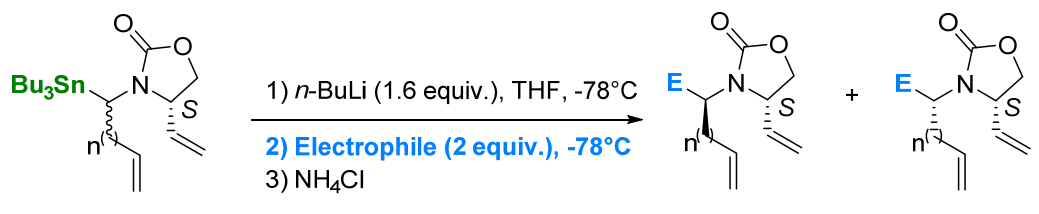

$3 \mathbf{a}, \mathrm{n}=1 ; \mathbf{3 b}, \mathrm{n}=\mathbf{2}$

A. With cyclohexanone as electrophile

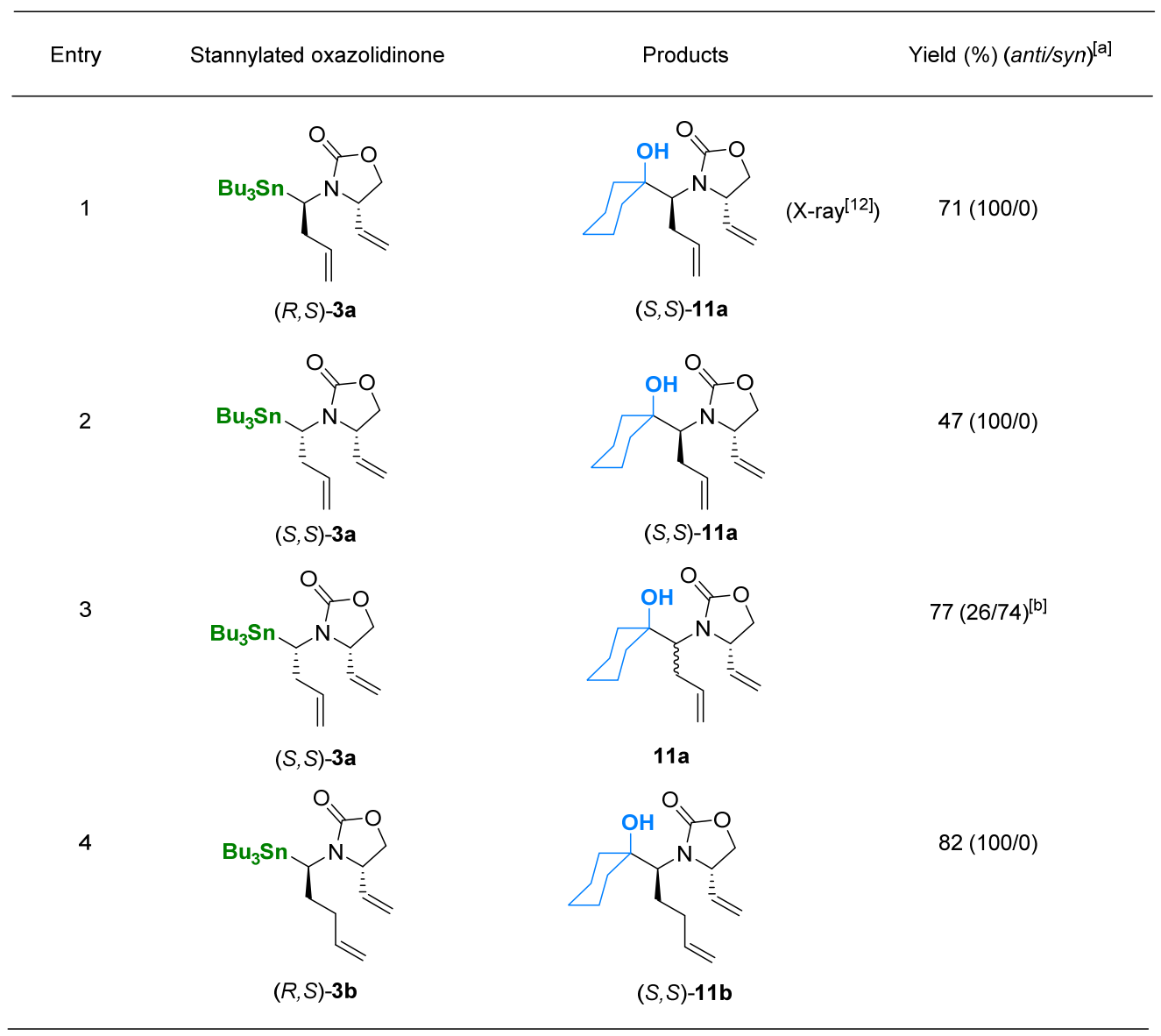

B. With other electrophiles starting from $(R, S)-3 a$

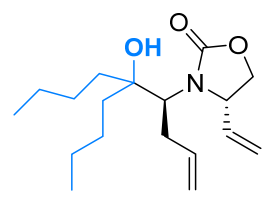

(S, S)-12a, 30\% anti/syn $=100 / 0^{[c]}$

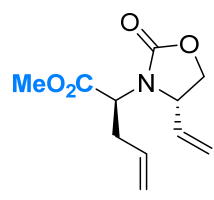

(S, S)-13a, 76\% anti/syn $=97 / 3^{[\mathrm{d}]}$

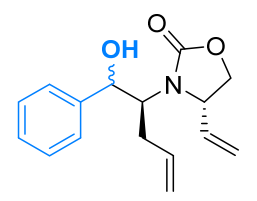

14a, $74 \%$

anti/syn $=100 / 0$ $d r=58 / 42^{[\mathrm{a}, \mathrm{e}, \mathrm{f}]}$

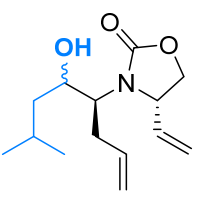

15a, $81 \%$

anti/syn $=100 / 0$ $d r=50 / 50^{[a, e, f]}$

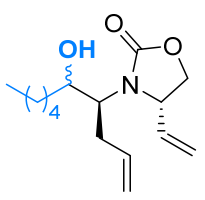

16a, $76 \%$ anti/syn $=100 / 0$ $d r=50 / 50^{[\mathrm{e}, \mathrm{f}, \mathrm{g}]}$

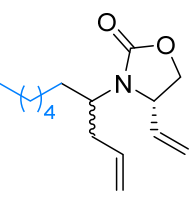

$17 \mathrm{a}, 71 \%$ anti/syn $=65 / 35^{[a, h]}$

${ }^{[a]}$ The ratio anti/syn was determined by GC on the crude; anti/syn are defined by the relative position of the allyl (or butenyl) and the vinyl moieties; the configuration of the anti isomer is $(S, S)$ if electrophile is a ketone, an aldehyde or $\mathrm{CO}_{2}$ and $(R, S)$ with a $n$-alkyl iodide.

${ }^{[b]}$ The reaction was carried out at $-100^{\circ} \mathrm{C}$.

[c] The reaction temperature was increased from $-78^{\circ} \mathrm{C}$ to $-50^{\circ} \mathrm{C}$ for dissolving nonanone.

[d] $\mathrm{CO}_{2}$ (g) was used and the crude was treated with $\mathrm{TMSCHN}_{2}$ (1.3 equiv.), $\mathrm{C}_{6} \mathrm{H}_{6}: \mathrm{MeOH}=4: 1$.

[e] The reaction temperature was $-90^{\circ} \mathrm{C}$ to avoid the intramolecular acyl transfer reaction.

${ }^{[f]}$ Diastereomers were separated by column chromatography on silica gel. The absolute configuration of $(S, S, S)$-14a (the minor one) was deduced from that of $(S, S, S)$-7a determined by X-ray diffraction. The absolute configurations of 15a and 16a were deduced from the comparison of their NMR data and $R_{F}$.

${ }^{[\mathrm{g}]}$ Determined by NMR on the crude.

[h] Unseparated mixture of diastereomers; $\mathrm{CuCN} .2 \mathrm{LiCl}$ ( 0.5 equiv.) and 1-iodohexane (1.8 equiv.) were used; the configuration of $\mathbf{1 7}$ a was deduced from that of 19a. 
Table 3. Ring-closing metathesis of dienyloxazolidinones 11-17.

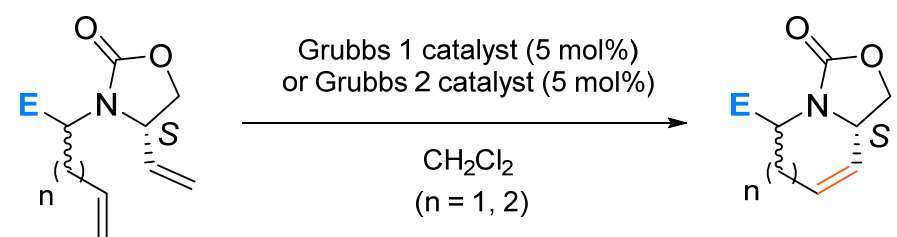<smiles>[Y10][14CH2][14CH2][C@@H]1C=CC[C@H](C2(O)CCCC2)N2C(=O)OC[C@H]12</smiles>

$(S, S)-5 a$ from $(S, S)-\mathbf{1 1 a}$ Grubbs $1,3 \mathrm{~h}, 25^{\circ} \mathrm{C}, 78 \%$ Grubbs $2,1.5 \mathrm{~h}, 40^{\circ} \mathrm{C}, 96 \%$<smiles></smiles>

$(R, S)-5 \mathbf{a}$ from $(R, S)-\mathbf{1 1 a}$ Grubbs $2,1 \mathrm{~h}, 40^{\circ} \mathrm{C}, 89 \%$<smiles>C#CC[C@H]1COC(=O)N1[C@H]1CCC=CCC1(O)CCC</smiles>

(S,S)-5b from (S,S)-11b Grubbs 1, [a] $12 \mathrm{~h}, 25^{\circ} \mathrm{C}, 51 \%$ Grubbs $2,1.5 \mathrm{~h}, 40^{\circ} \mathrm{C}, 79 \%$ $\left(5 \mathbf{b} / 5 b^{\prime}=89 / 11\right)$<smiles>O=C1OC[C@H]2C=CC[C@@H]([C@H](O)c3ccccc3)N12</smiles>

$(R, S, S)-\mathbf{7 a}$ from $(R, S, S)-\mathbf{1 4 a}$ Grubbs $2,2.5 \mathrm{~h}, 40^{\circ} \mathrm{C}, 80 \%$<smiles>CC(C)C[C@H](O)[C@H]1CC=C[C@@H]2COC(=O)N21</smiles>

$(R, S, S)-8 \mathbf{a}$ from $(R, S, S)-15 \mathbf{a}$ Grubbs $1,1 \mathrm{~h}, 25^{\circ} \mathrm{C}, 95 \%$<smiles>CCCCCC(O)[C@@H]1CC=C[C@@H]2COC(=O)N12</smiles>

$(R, S, S)-9 \mathbf{a}$ from $(R, S, S)-\mathbf{1 6 a}$ Grubbs $2,{ }^{[a]} 4 \mathrm{~h}, 40^{\circ} \mathrm{C}, 88 \%$

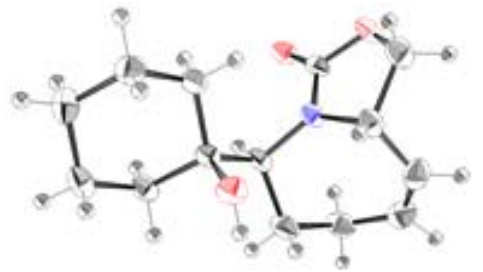<smiles>COC(=O)[C@@H]1CC=C[C@@H]2COC(=O)N12</smiles>

$(S, S)-6 \mathbf{a}$ from $(S, S)-\mathbf{1 3 a}$ Grubbs $1,2 \mathrm{~h}, 25^{\circ} \mathrm{C}, 90 \%$ Grubbs $2,3 \mathrm{~h}, 40^{\circ} \mathrm{C}, 87 \%$

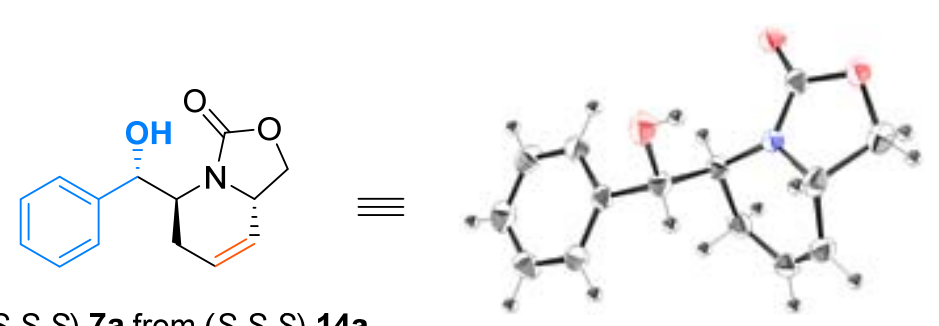

$(S, S, S)-\mathbf{7} \mathbf{a}$ from $(S, S, S)-\mathbf{1 4 a}$ Grubbs $2,2.5 \mathrm{~h}, 40^{\circ} \mathrm{C}, 71 \%$<smiles>CC(C)C[C@H](O)[C@H]1CC=C[C@@H]2COC(=O)N21</smiles>

$(S, S, S)-\mathbf{8 a}$ from $(S, S, S)-\mathbf{1 5 a}$ Grubbs $1,1 \mathrm{~h}, 25^{\circ} \mathrm{C}, 87 \%$<smiles>CCCCC[C@H](O)[C@H]1CC=C[C@@H]2COC(=O)N21</smiles>

$(S, S, S)-\mathbf{9 a}$ from $(S, S, S)-\mathbf{1 6 a}$ Grubbs $2,{ }^{[a]} 4 \mathrm{~h}, 40^{\circ} \mathrm{C}, 90 \%$<smiles>CCCCC(O)(CCCC)[C@@H]1CC=C[C@H]2COC(=O)N21</smiles>

$(S, S)-\mathbf{1 8 a}$ from $(S, S)-\mathbf{1 2 a}$ Grubbs $2,6 \mathrm{~h}, 40^{\circ} \mathrm{C}, 63 \%$<smiles>CCCC1CC=C[C@@H]2COC(=O)N12</smiles>

$(R, S+S, S)-19 \mathbf{a}$ from $(R, S+S, S)-17 \mathbf{a}$ Grubbs $1,2 \mathrm{~h}, 25^{\circ} \mathrm{C}, 84 \%$ $(R, S) /(S, S)=65 / 35^{[b]}$

[a] $10 \mathrm{~mol} \%$ of Grubbs catalyst used.

$[\mathrm{b}]$ The diastereomers $(R, S)-19 \mathrm{a}$ and $(S, S)-19 \mathrm{a}$ were separated by chromatography. Their absolute configurations were confirmed by NOESY NMR experiments. 


\section{Discussion}

The results displayed in Table 2 indicate that the sequence involving a Sn-Li transmetalation reaction with $n$ BuLi followed by an electrophilic trapping applied to 3a proceeds with a very high anti selectivity regardless of the configuration of 3a. When the reaction is carried out at $-78^{\circ} \mathrm{C}$ on diastereomer $(R, S)-\mathbf{3 a}$, the reaction leads selectively to the anti $(S, S)$-product. Starting from diastereomer $(S, S)-\mathbf{3 a}$, the selectivity is found to be temperature dependent. At $-78^{\circ} \mathrm{C}$ or at $-90^{\circ} \mathrm{C}$, the anti $(S, S)$-product is also selectively obtained, while a mixture of syn and anti products in a 3/1 ratio was obtained when the reaction is performed at $-100^{\circ} \mathrm{C}$. This high diastereoselectivity can be explained by the occurrence of a thermodynamic resolution. Under the experimental conditions, the configurational stability of intermediates $\mathbf{A}$ and $\mathbf{B}$ is dependent on the relative position of the allyl (or butenyl) and the vinyl moieties (Scheme 3). When the reaction is carried out at $-78^{\circ} \mathrm{C}$ on $(R, S)-3 \mathbf{a}$, the initially generated organolithium intermediate $\mathbf{A}$ is the more stable one and does not epimerize significantly into $\mathbf{B}$. Therefore, intermediate $\mathbf{A}$ is trapped by the electrophile with complete retention of configuration. A similar reasoning can be held for $(R, S)-\mathbf{3 b}$. On the other hand, when starting from $(S, S)-\mathbf{3 a}$, the more sterically hindered organolithium intermediate $\mathbf{B}$ is initially generated. At $-78^{\circ} \mathrm{C}$, it epimerizes and leads to $\mathbf{A}$ along with side reaction products before the electrophilic trapping. The epimerization of the stereogenic centre is fast and the ratio of the product is a reflection of the ratio of the diastereomeric organolithium complexes. ${ }^{[16]}$ When the reaction is carried out at a lower temperature, the epimerization is slowed down and can be partially avoided, affording mixture of the two diastereomers. This qualitative mechanism based on the experimental results is fully supported by DFT calculations at the BMK/cc-pVDZ level of theory. Based on computed free energies at $-78^{\circ} \mathrm{C}$, and taking into account the solvent effects, the intermediate $\mathbf{B}$ was found $1.5 \mathrm{kcal} / \mathrm{mol}$ less stable than A (Scheme 3). It means that under thermodynamic control, the occurrence of an equilibrium between the syn and anti-organolithium intermediates will result in a high prevalence of the anti-isomer (A) which would represent about $99 \%$ of the total population. When the reaction is carried out at $-100^{\circ} \mathrm{C}$, the reaction remains partially under kinetic control affording a 3/1 mixture of diastereomers.

When 1-iodohexane was used as electrophile (Table 2 and supporting information), the conversion of the organolithium intermediate into an organocopper reagent is required. It induces a dramatic effect on the diastereoselectivity of the reaction, presumably due to a modification of the reaction mechanism of the copper intermediate with the electrophile, which may proceed by a single electron transfer. ${ }^{[17],[18]}$

When considering the transmetalation of the fused ring systems tributylstannyl dehydropiperidine / oxazolidinone $4 \mathbf{a}$, an enhanced selectivity is observed. It leads to the cis $(R, S)$-product as unique diastereomer regardless of the configuration of the stannylated precursor, but with a drop in the yield when starting from the trans stannylated precursor (Table 1). In these cases, no trace of trans product can be observed by achieving the transmetalation of trans $(R, S)-\mathbf{4 a}$ at temperatures as low as $-100^{\circ} \mathrm{C}$, indicating a strong preference for the cis-configuration in the anionic species. The situation is similar in dehydroazepanes series. The cis isomer is selectively obtained regardless of the configuration of $\mathbf{4 b}$, with a drop in the yields when starting from the trans precursor (Table 1, entries 3,4 ). 
This high stereoselectivity can be explained by considering the structure of the organolithium intermediate. The cis-isomer furnished an intermediate which adopts a "ridge tile" shape and places the lithium in an adequate position for an intramolecular coordination with the oxazolidinone carbonyl.

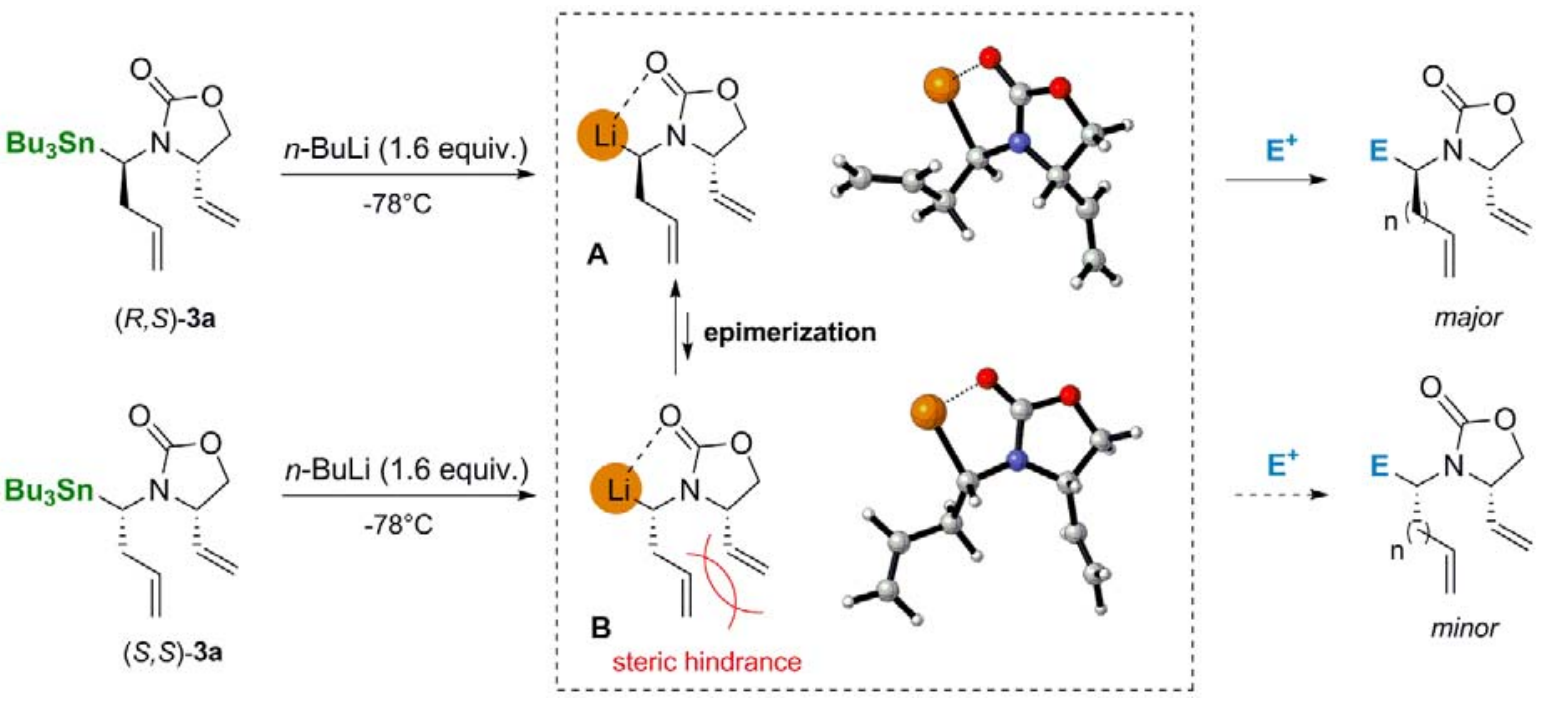

Scheme 3. Equilibration of organolithium species generated from $(R, S)-\mathbf{3 a}$ and $(S, S)-\mathbf{3 a}$, and their computed structures at the BMK/cc-pVDZ level of theory.

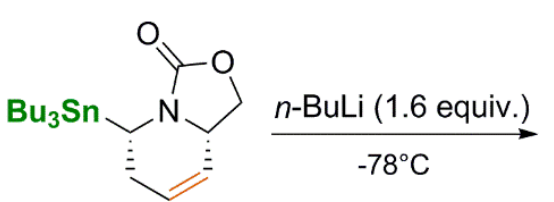

$(S, S)-4 a$

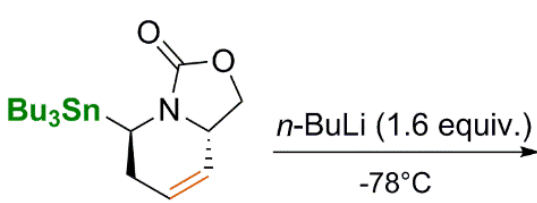

$(R, S)-\mathbf{4 a}$

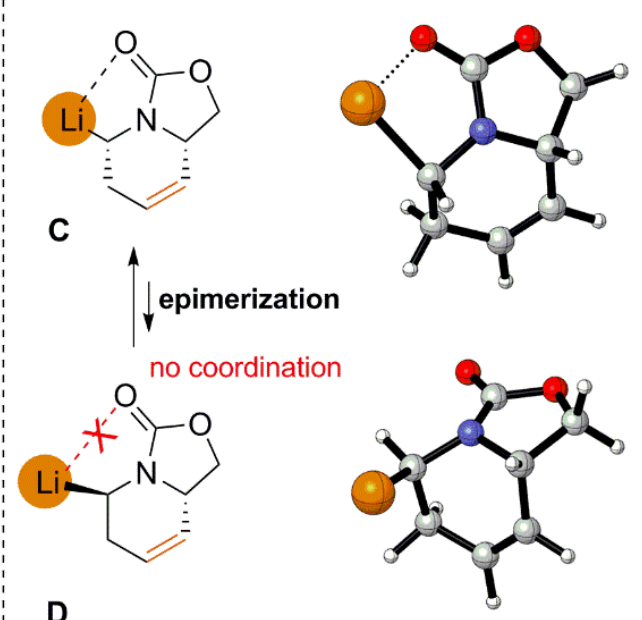

D

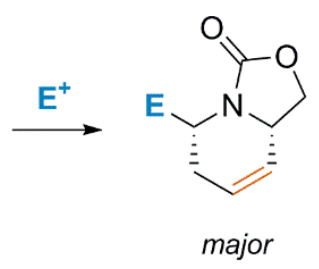

$\mathrm{E}^{+}$<smiles>O=C1OC[C@@H]2C=CC[C@H](F)N12</smiles>

minor

Scheme 4. Equilibration of organolithium species generated from $(R, S)-\mathbf{4 a}$ and $(S, S)-\mathbf{4 a}$, and their computed structures at the BMK/cc-pVDZ level of theory

Indeed, the quantum mechanical calculations predict a short $\mathrm{Li} \cdots \mathrm{O}$ distance, $1.896 \AA$ (Scheme 4, intermediate $\mathbf{C}$ ), away below the sum of the van der Waals radii of lithium and oxygen ( $3.33 \AA$ ).

In the lithiated species obtained from the trans-isomer, the relative orthogonal positions of lithium and oxazolidinone carbonyl does not allow such stabilizing coordination (Scheme 4, intermediate D). According to the free energies calculated at the BMK/cc-pVDZ level of theory, the intermediate $\mathbf{D}$ is less stable than $\mathbf{C}$ by $14.7 \mathrm{kcal} / \mathrm{mol}$ in $\mathrm{THF}$ at $-78^{\circ} \mathrm{C}$. Therefore, while cis configuration is completely maintained when starting from cis-4a, a complete epimerization arises when starting from trans-4a. Here again, the epimerization reaction occurs very fast under the experimental conditions used. 
The last part of the study (Table 3) points out the possibility to convert efficiently adducts 11a-17a and 11b into the corresponding dehydropiperidines and dehydroazepanes through ring-closing metathesis. Therefore, since adducts 11a-16a and 11b were obtained selectively as anti isomers, this strategy opens the route to trans dehydropiperidines.

\section{Conclusion}

The control of the configurational stability of the organolithium species obtained by transmetalation of stannylated oxazolidinones $\mathbf{3}$ and $\mathbf{4}$ by $n$-butyllithium allowed a highly diastereoselective synthesis of 2,6disubstituted dehydropiperidines (and 2,7-disubstituted dehydroazepanes). The stereochemical trends are rationalized by considering the difference of stabilization brought by the lithium-carbonyl coordination, which was estimated by DFT calculations as $1.5 \mathrm{kcal} / \mathrm{mol}$ for the organolithium species derived from $\mathbf{3 a}$ and as 14.7 $\mathrm{kcal} / \mathrm{mol}$ for the organolithium species derived from $4 \mathbf{a}$.

Thus, an efficient stereodivergent synthesis of (S,S)-trans or (R,S)-cis 2,6-disubstituted dehydropiperidines has been achieved starting from 3a. Using the reaction sequence: Sn-Li transmetalation/electrophilic trapping followed by a ring-closing metathesis, the $(S, S)$-trans 2,6-disubstituted dehydropiperidines are exclusively obtained, while the inversion of the reaction sequence affords $(R, S)$-cis 2,6-disubstituted dehydropiperidines. The same strategy remains valid in dehydroazepanes series. Application of this methodology to the synthesis of bioactive polysubstituted piperidines and iminosugars C-glycosides is currently under investigation.

\section{Experimental Section}

The general procedures are fully described in supporting information.

\section{Preparation and Characterization of Compounds}

Organotin precursor 1 was obtained by a transacetalisation reaction ${ }^{[11 a, 19]}$ between diethoxymethyltributyltin and (S)-vinylglycinol protected as $\mathrm{N}-\mathrm{CO}_{2} \mathrm{Me}^{2}{ }^{[20]}$ Details of the procedure have been previously reported ${ }^{[4]}$ together with the identification of cis and trans isomers which was established on the basis of their NMR data. ${ }^{[21]}$ Compound 2 was obtained by ring opening of $\mathbf{1}$ by soft alkenylmetals in the presence of Lewis acids and converted into oxazolidinone $\mathbf{3}$ before being submitted to ring-closing metathesis to afford 4. Compounds 2-4 have been already prepared and fully characterized..$^{[4]}$

\section{General procedure for Sn-Li transmetalation and electrophilic trapping of 3 or 4.}

In a Schlenk tube, stannyl oxazolidinone $(1 \mathrm{mmol})$ was dissolved in THF $(10 \mathrm{~mL})$ and the solution was cooled to $-78^{\circ} \mathrm{C}$ and kept under argon before slow dropwise addition of $n$-butyllithium $(1 \mathrm{~mL}, 1.6 \mathrm{M}$ in hexanes, $1.6 \mathrm{mmol})$ to the solution which turned to a slight yellow colour. Once this addition was complete, the solution was allowed to stir for $20 \mathrm{~min}$ at $78^{\circ} \mathrm{C}$ before dropwise addition of electrophile $(2 \mathrm{mmol})$. The reaction was quenched at $-78^{\circ} \mathrm{C}$ by addition of saturated aqueous $\mathrm{NH}_{4} \mathrm{Cl}$ after $20 \mathrm{~min}$. The aqueous phase was extracted with diethyl ether $(3 \times 20 \mathrm{~mL})$ and the combined organic 
extracts were dried $\left(\mathrm{MgSO}_{4}\right)$, filtered, and concentrated under vacuum. Purification was carried out by flash chromatography on silica gel.

\section{General procedure for ring closing metathesis of dienyloxazolidinones 11-17 into bicyclic oxazolidinones 5-9 and 18-}

19.

To a solution of dienyloxazolidinones $(0.65 \mathrm{mmol})$ in dichloromethane $\left(\mathrm{c}=0.005 \mathrm{~mol} . \mathrm{L}^{-1}\right)$ was added Grubbs catalyst $(0.032 \mathrm{mmol})$ and the reactive mixture was stirred at $25^{\circ} \mathrm{C}$ for Grubbs 1 catalyst and $40^{\circ} \mathrm{C}$ for Grubbs 2 catalyst. After complete conversion, DMSO $(0.11 \mathrm{~mL}, 1.62 \mathrm{mmol})$ was added and the solution was stirred overnight. The reaction mixture was concentrated under reduced pressure and the purification was carried out by flash chromatography on silica gel.

All the characterization data and NMR spectra of new compounds are given in supplementary information.

CCDC 718901, 723326 and 736227 contain the supplementary crystallographic data for this paper. These data can be obtained free of charge via www.ccdc.cam.ac.uk/data_request/cif, or by emailing data_request@ccdc.cam.ac.uk, or by contacting The Cambridge Crystallographic Data Centre, 12 Union Road, Cambridge CB2 1EZ, UK; fax: +44 1223 336033 .

\section{Acknowledgements}

We gratefully acknowledge the Université de Nantes, the "Centre National de la Recherche Scientifique" (CNRS). A.L. acknowledges the "Institut de Chimie des Substances Naturelles, ICSN" for a PhD grant.

\section{References}

[1] a) F.-X. Felpin, J. Lebreton, Curr. Org. Chem. 2004, 1, 83-109; b) J. Cossy, Chem. Rec. 2005, 5, 70-80; c) N. Toyooka, in Asymmetric Synthesis of Nitrogen Heterocycles (Ed.: J. Royer), Wiley, Weinheim, 2009, pp. 95-138; d) R. Vardanyan, in Piperidine-Based Drug Discovery (Ed.: R. Vardanyan), Elsevier, 2017, pp. 299-332; e) P. Goel, O. Alam, M. J. Naim, F. Nawaz, M. Iqbal, M. I. Alam, Eur. J. Med. Chem. 2018, 157, 480-502.

[2] a) N. Asano, R. J. Nash, R. J. Molyneux, G. W. J. Fleet, Tetrahedron Asymmetry 2000, 11, 1645-1680; b) V. H. Lillelund, H. H. Jensen, X. Liang, M. Bols, Chem. Rev. 2002, 102, 515-554; c) P. Compain, O. R. Martin, Iminosugars: Past, Present and Future, John Wiley \& Sons, Ltd, 2008.

[3] a) S. Mix, S. Blechert, Adv. Synth. Catal. 2007, 349, 157-160; b) G. Horne, F. X. Wilson, J. Tinsley, D. H. Williams, R. Storer, Drug Discov. Today 2011, 16, 107-118; c) P. Compain, Molecules 2018, 23, 1658.

[4] A. Lumbroso, V. Coeffard, D. Gatineau, S. Stecko, I. Beaudet, J.-P. Quintard, E. Le Grognec, Eur. J. Org. Chem. 2016, 5146-5159.

[5] a) Y. Troin, M.-E. Sinibaldi, in Asymmetric Synthesis of Nitrogen Heterocycles (Ed.: J. Royer), Wiley, Weinheim, 2009, pp. 139-186; b) A. G. Meyer, J. A. Smith, C. Hyland, C. C. Williams, A. C. Bissember, T. P. Nicholls, in Progress in Heterocyclic Chemistry, Vol. 28 (Eds.: G. W. Gribble, J. A. Joule), Elsevier, 2016, pp. 579-622.

[6] a) M. Pereyre, J.-P. Quintard, A. Rahm, Tin in Organic Synthesis, Butterworths, London, 1987; b) C. Rim, D. Y. Son, Arkivoc 2006, 265-291.

[7] a) W. C. Still, C. Sreekumar, J. Am. Chem. Soc. 1980, 102, 1201-1202; b) J. S. Sawyer, T. L. Macdonald, G. J. McGarvey, J. Am. Chem. Soc. 1984, 106, 3376-3377; c) J. S. Sawyer, A. Kucerovy, T. L. Macdonald, G. J. McGarvey, J. Am. Chem. Soc. 1988, 110, 842-853; d) P. Lesimple, J.-M. Beau, P. Sinay, J. C. S. Chem. Commun. 1985, 894-895; e) D. S. Matteson, P. B. Tripathy, A. Sarkar, K. M. Sadhu, J. Am. Chem. Soc. 1989, 111, 43994402; f) K. Tomooka, T. Igarashi, M. Watanabe, T. Nakai, Tetrahedron Lett. 1992, 33, 5795-5798; g) K. Tomooka, N. Komine, T. Nakai, Tetrahedron Lett. 1997, 38, 8939-8942.

[8] a) R. E. Gawley, Q. Zhang, J. Am. Chem. Soc. 1993, 115, 7515-7516; b) R. E. Gawley, Q. Zhang, Tetrahedron 1994, 50, 6077-6088; c) I. Coldham, R. Hufton, D. J. Snowden, J. Am. Chem. Soc. 1996, 118, 5322-5323; d) J. M. Chong, S. B. Park, J. Org. Chem. 1992, 57, 2220-2222; e) V. Coeffard, I. Beaudet, J.-P. Quintard, E. Le 
Grognec, Chirality 2010, 22, 864-869; f) J.-P. Quintard, E. Le Grognec, in Comprehensive Chirality, Vol. 3 (Eds.: E. M. Carreira, H. Yamamoto), Elsevier, Amsterdam, 2012, pp. 751-779.

[9] P. Beak, A. Basu, D. J. Gallagher, Y. S. Park, S. Thayumanavan, Acc. Chem. Res. 1996, 29, 552-560.

[10] a) W. H. Pearson, A. C. Lindbeck, J. Am. Chem. Soc. 1991, 113, 8546-8548; b) W. H. Pearson, A. C. Lindbeck, J. W. Kampf, J. Am. Chem. Soc. 1993, 115, 2622-2636; c) K. Brickmann, R. Brückner, Chem. Ber. 1993, 126, 1227; d) V. Coeffard, E. Le Grognec, I. Beaudet, M. Lepeltier, V. Léat-Crest, J.-P. Quintard, Synthesis 2006, 4151-4158.

[11] a) V. Coeffard, J.-C. Cintrat, E. Le Grognec, I. Beaudet, J.-P. Quintard, J. Organomet. Chem. 2006, 691, 14881497; b) V. Coeffard, I. Beaudet, M. Evain, E. Le Grognec, J.-P. Quintard, Eur. J. Org. Chem. 2008, 3344-3351; c) V. Coeffard, E. Le Grognec, I. Beaudet, M. Evain, J.-P. Quintard, J. Org. Chem. 2009, 74, 5822-5838.

[12] A. Lumbroso, I. Beaudet, L. Toupet, E. Le Grognec, J.-P. Quintard, Org. Lett. 2013, 15, 160-163.

[13] Our investigations on the influence of the temperature and on the absolute configuration of the compounds resulting from the acyl transfer reaction are reported in supporting information.

[14] a) D. A. Evans, M. M. Morrissey, R. L. Dorow, J. Am. Chem. Soc. 1985, 107, 4346-4348; b) C. Aciro, S. G. Davies, A. C. Garner, Y. Ishii, M.-S. Key, K. B. Ling, R. S. Prasad, P. M. Roberts, H. Rodriguez-Solla, C. O'Leary-Steele, A. J. Russell, H. J. Sanganee, E. D. Savory, A. D. Smith, J. E. Thomson, Tetrahedron 2008, 64, 9320-9344.

[15] a) B. Schmidt, J. Org. Chem. 2004, 69, 7672-7687; b) S. Fustero, M. Sánchez-Roselló, D. Jiménez, J. F. SanzCervera, C. del Pozo, J. L. Aceña, J. Org. Chem. 2006, 71, 2706-2714.

[16] a) P. Beak, D. R. Anderson, M. D. Curtis, J. M. Laumer, D. J. Pippel, G. A. Weisenburger, Acc. Chem. Res. 2000, 33, 715-727; b) I. Coldham, S. Dufour, T. F. N. Haxell, J. J. Patel, G. Sanchez-Jimenez, J. Am. Chem. Soc. 2006, 128, 10943-10951; c) I. Coldham, J. J. Patel, S. Raimbault, D. T. E. Whittaker, Chem. Commun. 2007, 45344536; d) I. Coldham, N. S. Sheikh, Top. Stereochem. 2010, 26, 253-293.

[17] E. C. Ashby, D. Coleman, J. Org. Chem. 1987, 52, 4554-4565.

[18] S. Mori, E. Nakamura, in Modern Organocopper Chemistry (Ed.: N. Krause), Wiley-VCH Verlag GmbH, 2002, pp. 315-346.

[19] a) J.-C. Cintrat, V. Léat, J.-L. Parrain, E. Le Grognec, I. Beaudet, L. Toupet, J.-P. Quintard, Organometallics 2004, 23, 943-945; b) J.-C. Cintrat, V. Leat-Crest, J.-L. Parrain, E. Le Grognec, I. Beaudet, J.-P. Quintard, Eur. J. Org. Chem. 2004, 4251-4267.

[20] A. Lumbroso, V. Coeffard, E. Le Grognec, I. Beaudet, J.-P. Quintard, Tetrahedron Lett. 2010, 51, 3226-3228.

[21] a) J.-C. Cintrat, V. Léat-Crest, J.-L. Parrain, E. Le Grognec, I. Beaudet, L. Toupet, J.-P. Quintard, Eur. J. Org. Chem. 2004, 4268-4279; b) G. Casella, F. Ferrante, G. Saielli, Org. Biomol. Chem. 2010, 8, 2711-2718. 
Sn-Li Transmetalation of $\alpha$-Aminoorganostannanes for the Stereoselective Synthesis of Substituted Dehydropiperidines and Dehydroazepanes

Adv. Synth. Catal. Year, Volume, Page - Page

Alexandre Lumbroso, ${ }^{\mathrm{a}}$ Isabelle Beaudet, ${ }^{\mathrm{a}}$ Jean-Paul Quintard, ${ }^{\mathrm{a}}$ Cécile Fraisse, ${ }^{\mathrm{a}}$ Nicolas Galland, ${ }^{\mathrm{b}}$ Loïc Toupet, ${ }^{b}$ Erwan Le Grognec ${ }^{\text {a }}$

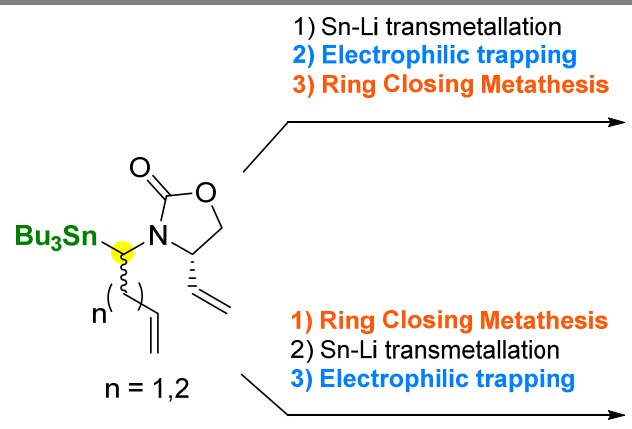

${ }_{n} Y_{=}^{\mathrm{O}}$

$97-100 \%$ S,S

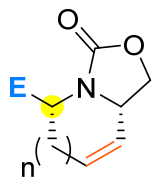

$100 \% R, S$ 